\title{
The Impact of Emotional Intelligence on Mental Health of Pakistani Nurses: The Mediator Role of Organizational Commitment
}

\author{
Norhani Bakri ${ }^{1} \&$ Nazim Ali ${ }^{1}$ \\ ${ }^{1}$ Faculty of Management, Universiti Teknologi Malaysia, Malaysia \\ Correspondence: Nazim Ali, Faculty of Management, Universiti Teknologi Malaysia, Malaysia. E-mail: \\ nazimali1000@gmail.com
}

Received: December 25, 2014 Accepted: March 2, 2015 Online Published: May 16, 2015

doi:10.5539/ass.v11n13p151

URL: http://dx.doi.org/10.5539/ass.v11n13p151

\begin{abstract}
The present study investigates the mediating effect of organizational commitment between emotional intelligence (EI) and mental health (MH). The participants of the study were 252 nurses working in six big districts of KPK (Peshawar, Mardan, Swat, Sawabi, Charsadda \& Nowshehra), Pakistan. Data were collected through Organizational Commitment Scale (Meyer, Allen, \& Smith, 1993), The Hospital Anxiety and Depression Scale (Zigmond \& Snaith, 1983) and EI Scale (Wong \& Law, 2002). Both EI and organizational commitment were significantly related to MH. The results of Structure Equation Modeling (SEM) explored that organizational commitment partially mediated the relationship between EI and MH. The final three factor model explored a significant path from EI to MH via organizational commitment. The findings discuss the effect of EI on MH.
\end{abstract}

Keywords: emotional intelligence, organizational commitment, mental health, nurses, Pakistan

\section{Introduction}

Emotional intelligence, organizational commitment and MH play a vital role in health care organizations. In tempestuous working environment employees move heaven and earth to create and maintain best health care of patients with limited resources (Laschinger, Finegan, \& Shamian, 2001). As hospitals are the main providers of health care services to patients, it is a critical research issue to attract and retain nurses (Tallman \& Bruning, 2005). This study aims at investigating the relationship among emotional intelligence, organizational commitment, $\mathrm{MH}$ and the mediating impact of organizational commitment between emotional intelligence and $\mathrm{MH}$ of Pakistani nurses. Emotional intelligence, organizational commitment and $\mathrm{MH}$ are thought to have a significant impact on the performance of hospitals. Recent research has diagnosed that emotional intelligence affect the performance of organizations' employees (Cote \& Miners, 2006).

IE is "the ability to monitor one's own and others' feelings and emotions, to discriminate among them and to use this information to guide one's thinking and actions' (Mayer, Salovey, Caruso, \& Sitarenios, 2001). Wong and Law (2002) proposed the following four dimensions of emotional intelligence:

1) Self-emotion Appraisal (SEA) which refers to an employee's ability to comprehend and express his/her emotions.

2) Others' Emotion Appraisal (OEA) which refers to an employee's ability to comprehend and express the emotions of those who are around him/her.

3) Use of Emotion (UOE) which refers to the ability of an employee to use their emotions for making and achieving of goals.

4) Regulation of Emotion (ROE) which refers to the ability of an employee to control his/her emotions and make the best use of them for enhancing performance.

Organizational commitment is a psychological attachment of employees to organization for their willingness to achieve the organizations goals. Meyer and Allen (1997) defined commitment as "emotional attachment to an organization; a goals and values which results in willingness to exert optimal effort to achieve the organizations goals". Organizational commitment has three dimensions comprised of affective commitment, continuance commitment and normative commitment (Meyer \& Allen, 1991). Affective commitment is an active bond of psychological attachment of employees to their organization. Continuance commitment is the feelings of longing 
not to divorce from the organization because of losing the benefits earned. Normative commitment is the sense of responsibility for the organization.

Studies have revealed that health professionals such as doctors and nurses were in high risk due to many adverse effects of nerve-wracking workplace (Kirkcaldy \& Martin, 2000; Tyler \& Cushway, 1998). Work stressors have a significant bearing on nurses' behaviors that culminate in some serious mental problems such as depression, insomnia, anxiety and feelings of inadequacy (Wong, Leung, So, \& Lam, 2001). Nurses are extremely exposed to several stress-related forces such as high workload, discrimination, conflict with doctors, dealing with patients, and death of patients (French, Lenton, Walters, \& Eyles, 2000; Marshall, 1980). Nurses often face many other health problems resulting from bullying and shift working (Ball, Pike, Cuff, Mellor-Clark, \& Connell, 2002; Bøggild \& Knutsson, 1999). According to the National Institute for Occupational Safety and Health, psychological disorders are among the ten top occupational injuries or diseases and almost $75 \%$ of nurses seek psychiatric consultation (Levi, 1990).

A very few studies have investigated the relationship between emotional intelligence and organizational commitment and MH. Employees who have high emotional intelligence will have a high level of commitment to their organization. For example, Nikolaou and Tsaousis (2002), with two-hundred and twelve health professionals including social workers, and nurses, explored a significant positive correlation between total EI and employees' commitment to the organization (.53). EI was measured by four subscales, namely, perception and appraisal, control of emotions, use of emotions and understanding and reasoning. They also found a significant positive relationship between three subscale of EI (control of emotions and commitment, .42; use of emotions and commitment, .58 and understanding and reasoning and commitment, .25) and employees' commitment to the organization. Perception and appraisal did not show any positive significant relationship with employees' commitment to the organization -.03. Furthermore, they explored a significant negative correlation between total EI and occupational stress (-.59). All subscales of EI (perception and appraisal and occupational stress, -.23; control of emotions and occupational stress, -.54; use of emotions and occupational stress, -.55; and understanding and reasoning and occupational stress, -.19) were also found to have a significant negative correlation with occupational stress.

Slaski and Cartwright (2002), with three-hundred and twenty middle managers working for UK retailers, explored a significant negative correlation between total EI and distress (-.567) indicating that those managers who scored higher in EI scale were less exposed to stress, experienced better health and well-being and showed higher management performance. Moreover, they took five dimensions of emotional intelligence: intrapersonal, interpersonal, adaptability, stress management and general mood and exposed a significant negative correlation between intrapersonal and distress (-.544), interpersonal and distress (-.224), adaptability and distress (-.427), stress management and distress (-.434) and general mood and distress (-.528).

Guleryuz, Guney et al. (2008), with two-hundred and sixty seven nurses working in different department of hospitals, studied the relationship between four dimensions of EI explored a significant positive correlation between use of emotions and organizational commitment (.175) and regulation of emotions and organizational commitment (.186), while self-emotional appraisal and others' emotional appraisal did not show a significant relationship with organizational commitment. Moreover, the total EI and organizational commitment (.229) were significantly correlated.

Mohammadfar, Khan et al. (2009), with a sample of two-hundred and fifty primary and high schools' teachers from India, explored a significant negative correlation between EI and MH (-.55) and EI and physical health $(-.28)$ indicating that those teachers who are mentally intelligent will be psychologically and physically strong.

To summarize, a limited studies found the relationship between EI and organizational commitment (Güleryüz et al., 2008; Nikolaou \& Tsaousis, 2002) and EI and MH (Mohammadyfar et al., 2009; Slaski \& Cartwright, 2002). The present study investigates the mediating effect of organizational commitment between EI and MH of Pakistani nurses. No previous study was found that have tested the mediating effect of organizational commitment between EI and MH.

\section{Hypotheses}

1) There is a significant relationship between EI and organizational commitment of Pakistani nurses.

2) There is a significant relationship between EI and MH of Pakistani nurses.

3) Organizational commitment mediates the relationship between EI and MH of Pakistani nurses. 


\section{Methodology}

\subsection{Population and Sample}

Data were collected from 252 female nurses of six districts hospitals out of 26 districts of KPK, Pakistan from March to June 2014, through a questionnaire comprised of Organizational Commitment Scale (Meyer et al., 1993), The Hospital Anxiety and Depression Scale (Zigmond \& Snaith, 1983), and EI Scale (Wong \& Law, 2002), apart from demographic characteristics which were age, tenure, gender and marital status. A written informed consent to participate in the current study was received from nurses. Participants were informed that they were engaged in psychological study in which there were no correct or incorrect answers. In total, 255 questionnaires were distributed. Three questionnaires were disposed of because of incomplete information.

\subsection{Measurement}

\subsubsection{Self-Report Wong Law Emotional Intelligence Scale}

We used Self-Report Wong Law Emotional Intelligence Scale (Wong \& Law, 2002). WLEIS has four subscales corresponding to the four dimensions of Emotional Intelligence: Self-emotion Appraisal (SEA), Others' Emotion Appraisal (OEA), Use of Emotion (UOE) and Regulation of Emotion (ROE). Every dimension of EI has four items each. All items of EI were scored on 7 point Likert scale ranging from 1 "Strongly Disagree" to 7 "Strongly Agree". All dimensions of EI showed a very good reliability in current study. Cronbach's Alfa was 0.961 for SEA, 0.966 for ROE, 0.971 for OEA, and 0.973 for UOE. Confirmatory Factor Analysis confirmed the validity of EI Scale $($ Chi Square $=128.975$, Degree of Freedom $=100$, Probability $=0.027$, GFI $=0.942, \mathrm{CFI}=$ $0.995, \mathrm{RMR}=0.075, \mathrm{RMSEA}=0.034$ ).

\subsubsection{Organizational Commitment Scale}

Organizational commitment was measured by averaging the subscale of affective commitment, continuance commitment and normative commitment (Meyer et al., 1993). Each scale of organizational commitment has six items. Responses were elicited by using 7-point likert scale ranging from 1 "Strongly Disagree" to 7 "Strongly Agree". All scales revealed a very good reliability in present study. Cronbach's Alfa was 0.964 for AC, 0.931 for $\mathrm{CC}$ and 0.953 for NC. Confirmatory Factor Analysis confirmed the validity of the organizational commitment scale $($ Chi Square $=181.439$, Degree of Freedom $=132$, Probability $=0.003$, GFI $=0.928, \mathrm{CFI}=0.990, \mathrm{RMR}=$ 0.027 , RMSEA $=0.039$ ).

\subsubsection{The Hospital Anxiety and Depression Scale (HADS)}

Anxiety and depression of nurses were measured by HADS developed by (Zigmond \& Snaith, 1983). Anxiety and depression have seven items each. Responses were noted on 4 point likert scale ranging from 0 to 3.All scales revealed a very good reliability in present study. Cronbach's Alfa was 0.972 for Anxiety, 0.968 for Depression. Confirmatory Factor Analysis confirmed the validity of the MH Scale after regression weight of 1 was put on parameter depression. (Chi Square $=135.136$, Degree of Freedom $=76$, Probability $=0.000$, GFI $=$ $0.926, \mathrm{CFI}=0.987, \mathrm{RMR}=0.023, \mathrm{RMSEA}=0.056$ ).

\subsection{Data Analysis}

We used correlation to investigate the relationship between emotional intelligence, organizational commitment and $\mathrm{MH}$. We also used the test techniques implemented by (Baron \& Kenny, 1986) to find out the mediating effect of organizational commitment between EI and MH. According to Baron and Kenny (1986), for organizational commitment to be a mediator between EI and MH, four conditions should be satisfied. First, EI significantly predicts $\mathrm{MH}$. Second, EI significantly predicts organizational commitment. Third, organizational commitment significantly predicts MH. And finally, the relationship between EI and MH is reduced or insignificant upon the inclusion of organizational commitment. Data were analyzed by using Amos.

\section{Results}

Table 1. Correlation between emotional intelligence, organizational commitment and mental health

\begin{tabular}{llll}
\hline & Emotional Intelligence & Organizational Commitment & Mental Health \\
\hline Emotional Intelligence & 1 & $.457^{* *}$ & $-.311^{* *}$ \\
Organizational Commitment & $.457^{* *}$ & 1 & $-.280^{* *}$ \\
Mental Health & $-.311^{* *}$ & $-.280^{* *}$ & 1 \\
**. Correlation is significant at the 0.01 level (2-tailed). & & \\
\hline
\end{tabular}


The results of Table 1 extracted by using SPSS explored a positive significant relationship between EI and organizational commitment, a negative significant relationship between organizational commitment and $\mathrm{MH}$ and $\mathrm{EI}$ and $\mathrm{MH}$.

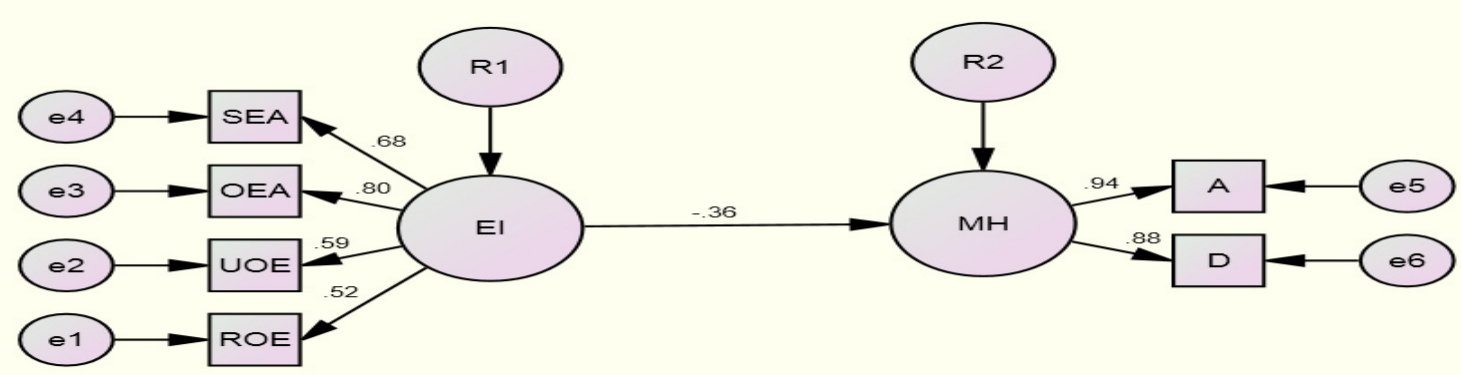

Figure 1. Direct path from emotional intelligence to mental health

EI = Emotional Intelligence; SEA = Self-emotion Appraisal; OEA = Others' Emotion Appraisal; UOE = Use of Emotion; ROE = Regulation of Emotion; $\mathrm{MH}=$ Mental Health; $\mathrm{A}=$ Anxiety; $\mathrm{D}=$ Depression

The results of Structural Equation Modeling (SEM), shown in Figure 1 explored that EI had a significant negative impact on MH of nurses. The two factors model of EI and MH showed a very good fit of the sample data. All values of Chi square, GFI, CFI, RMR, NFI, and RMSEA are in acceptable range. Chi square = 16.048; degree of freedom $=8$; probability level $=.042 ; \mathrm{CMIN} / \mathrm{DF}=2.006 ; \mathrm{GFI}=0.981 ; \mathrm{RMR}=0.050 ; \mathrm{NFI}=0.970$; $\mathrm{CFI}=0.985$; RMSEA $=0.063$. The value of beta between EI and MH is -0.36 indicating that EI significantly predicts MH of nurses. Thus, the first condition proposed by Baron and Kenny (1986) for testing the mediation effect of organizational commitment between EI and MH was satisfied.

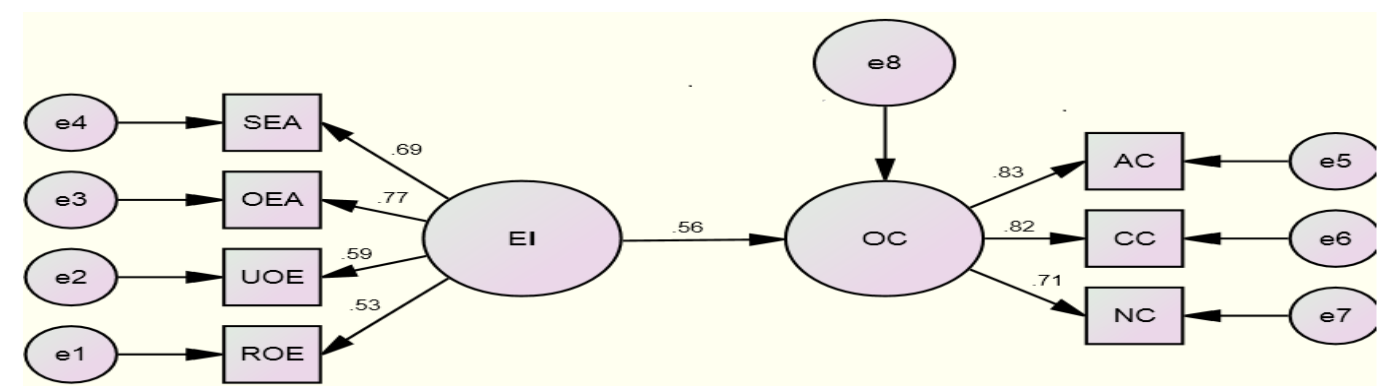

Figure 2. Direct path from emotional intelligence to organizational commitment

$\mathrm{EI}=$ Emotional Intelligence; SEA $=$ Self-emotion Appraisal; OEA = Others' Emotion Appraisal; UOE $=$ Use of Emotion; $\mathrm{ROE}=$ Regulation of Emotion; $\mathrm{OC}=$ Organizational Commitment; $\mathrm{AC}=$ Affective Commitment; $\mathrm{CC}$ $=$ Continuance Commitment $\mathrm{NC}=$ Normative Commitment

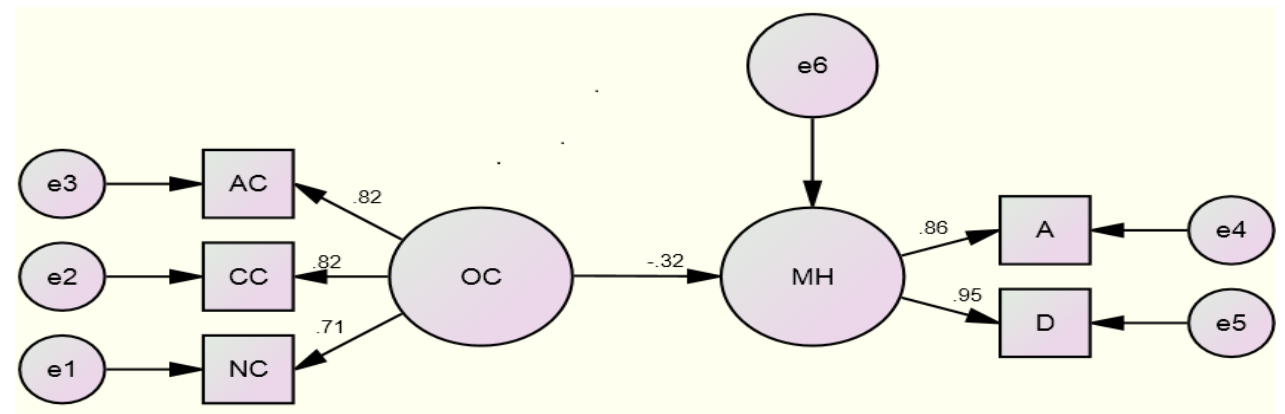

Figure 3. Direct path from organizational commitment to mental health

$\mathrm{OC}=$ Organizational Commitment; $\mathrm{AC}=$ Affective Commitment; $\mathrm{CC}=$ Continuance Commitment; $\mathrm{NC}=$ Normative Commitment and $\mathrm{MH}=$ Mental Health; $\mathrm{A}=$ Anxiety; $\mathrm{D}=$ Depression 
The results of Structural Equation Modeling (SEM) shown in Figure 2 explored that EI had a significant positive impact on organizational commitment of nurses. The two factors model of EI and organizational commitment showed a very good fit of the sample data. All values of Chi square, GFI, CFI, RMR, NFI, and RMSEA are in acceptable range. Chi square $=24.093$; degree of freedom $=13$; probability level $=.030 ; \mathrm{CMIN} / \mathrm{DF}=1.853 ; \mathrm{GFI}$ $=0.974 ; \mathrm{RMR}=0.047 ; \mathrm{NFI}=0.959 ; \mathrm{CFI}=0.980 ; \mathrm{RMSEA}=0.058$. The value of beta between $\mathrm{EI}$ and organizational commitment is 0.56 indicating that EI significantly predicts organizational commitment of nurses. Thus the second condition proposed by Baron and Kenny (1986) for testing the mediation effect of organizational commitment between EI and MH was also satisfied.

The results of Structural Equation Modeling (SEM) shown in Figure 3 also explored that organizational commitment had a significant negative impact on $\mathrm{MH}$ of nurses. The two factors model of organizational commitment and MH showed a very good fit of the sample data. All values of Chi square, GFI, CFI, RMR, NFI, and RMSEA are in acceptable range. Chi square $=10.801$; degree of freedom $=4$; probability level $=.029$; $\mathrm{CMIN} / \mathrm{DF}=2.7000 ; \mathrm{GFI}=0.983 ; \mathrm{RMR}=0.013 ; \mathrm{NFI}=0.982 ; \mathrm{CFI}=0.988 ; \mathrm{RMSEA}=0.082$. The value of beta between organizational commitment and $\mathrm{MH}$ is -0.32 indicating that organizational commitment significantly predicts MH of nurses. Thus the third condition proposed by Baron and Kenny (1986) for testing the mediation effect of organizational commitment between EI and MH was also met.

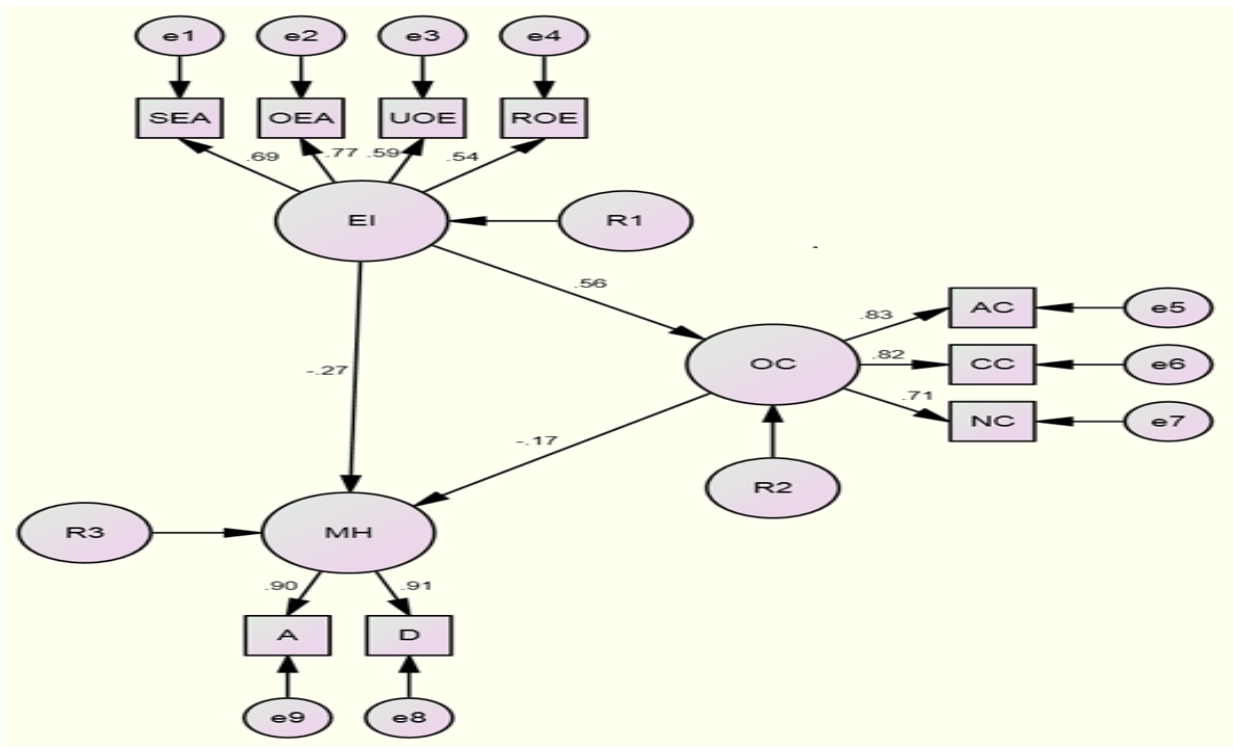

Figure 4. Path from emotional intelligence to mental health through organizational commitment

$\mathrm{EI}=$ Emotional Intelligence; SEA = Self-emotion Appraisal; OEA = Others' Emotion Appraisal; UOE = Use of Emotion; $\mathrm{ROE}=$ Regulation of Emotion; $\mathrm{OC}=$ Organizational Commitment; $\mathrm{AC}=$ Affective Commitment; $\mathrm{CC}=$ Continuance Commitment; $\mathrm{NC}=$ Normative Commitment and $\mathrm{MH}=$ Mental Health; $\mathrm{A}=$ Anxiety; $\mathrm{D}=$ Depression

As all the first three conditions proposed by Baron and Kenny (1986) were satisfied, the mediating effect of organizational commitment between EI and $\mathrm{MH}$ was tested. The model of all three variables fit the data very well. Chi square $=37.564 ;$ degree of freedom $=24 ;$ probability level $=.038 ; \mathrm{CMIN} / \mathrm{DF}=1.565 ; \mathrm{GFI}=0.969$; $\mathrm{RMR}=0.041 ; \mathrm{NFI}=0.959 ; \mathrm{CFI}=0.984 ; \mathrm{RMSEA}=0.047$;CLOSE $=0.525$. All values are in acceptable range Before the organizational commitment (mediator) was included, the impact of EI on MH was -0.36. After the inclusion of organizational commitment (Mediator), the impact of EI on MH decreased to -0.27. Organizational commitment mediated the relationship between EI and MH but the value of beta $(-0.27)$ is still significant indicated a partial mediation. The findings supported all the three hypotheses.

\section{Conclusion and Discussion}

The results revealed a significant positive path from EI to organizational commitment, a significant negative path from EI to $\mathrm{MH}$, a significant negative path from organizational commitment to $\mathrm{MH}$ and a significant negative path from EI to $\mathrm{MH}$ through organizational commitment. The results of this study explored that EI could partially affect $\mathrm{MH}$ of nurses through organizational commitment. The findings that EI has a significant negative 
relationship with MH are consistence with previous studies (Mohammadyfar et al., 2009; Slaski \& Cartwright, 2002). As EI was proved to have a significant impact on anxiety and depression of Pakistani nurses, it is advised to the administration of hospitals to pay heed towards reducing nurses' anxiety and depression and enhance their performance by providing training facility to nurses for improving their emotional intelligence. On the other hand, EI also explored a significant positive impact on organizational commitment. This finding is also consistent with previous studies (Güleryüz et al., 2008; Nikolaou \& Tsaousis, 2002), indicating that employees who are emotionally intelligent will demonstrate high level of organizational commitment. It is inevitable to increase organizational commitment by enhancing EI of nurses. Important strategies need be developed for achieving this objective. Organizational commitment indicated a mediator role between EI and anxiety and depression dimensions of MH. A strategy to increase the level of organizational commitment is indispensable, because it can easily mediate the relationship between EI and MH.

\section{Ethical Consideration}

Ethical issues (including Plagiarism, informed consent, misconduct, data fabrication and/or falsification, double publication and/or submission, redundancy etc) have been completely observed by the authors. There is no interest of conflicts.

\section{References}

Ball, J., Pike, G., Cuff, C., Mellor-Clark, J., \& Connell, J. (2002). RCN working well survey. Retrieved May, 2003, from http://www.rcn.org.uk/publications/pdf/working_well_survey_inside1/pdf

Baron, R. M., \& Kenny, D. A. (1986). The moderator-mediator variable distinction in social psychological research: Conceptual, strategic, and statistical considerations. Journal of personality and social psychology, 51(6), 1173. http://dx.doi.org/10.1037/0022-3514.51.6.1173

Bøggild, H., \& Knutsson, A. (1999). Shift work, risk factors and cardiovascular disease. Scandinavian journal of work, environment \& health, 85-99. http://dx.doi.org/10.5271/sjweh.410

Cote, S., \& Miners, C. T. (2006). Emotional intelligence, cognitive intelligence, and job performance. Administrative Science Quarterly, 51(1), 1-28.

French, S. E., Lenton, R., Walters, V., \& Eyles, J. (2000). An empirical evaluation of an expanded nursing stress scale. Journal of nursing measurement, 8(2), 161-178.

Güleryüz, G., Güney, S., Aydın, E. M., \& Aşan, Ö. (2008). The mediating effect of job satisfaction between emotional intelligence and organizational commitment of nurses: a questionnaire survey. International Journal of Nursing Studies, 45(11), 1625-1635. http://dx.doi.org/10.1016/j.ijnurstu.2008.02.004

Inventory, E. B. E. Q. (2002). Technical Manual. Multi-Health Systems: Inc.

Kirkcaldy, B. D., \& Martin, T. (2000). Job stress and satisfaction among nurses: individual differences. Stress and Health, 16(2), 77-89. http://dx.doi.org/10.1002/(SICI)1099-1700(200003)16:2<77::AID-SMI835> 3.3.CO;2-Q

Laschinger, H. K. S., Finegan, J., \& Shamian, J. (2001). The impact of workplace empowerment, organizational trust on staff nurses' work satisfaction and organizational commitment. Health Care Management Review, 26(3), 7-23. http://dx.doi.org/10.1097/00004010-200107000-00002

Levi, L. (1990). Occupational stress: Spice of life or kiss of death? American Psychologist, 45(10), 1142. http://dx.doi.org/10.1037/0003-066X.45.10.1142

Marshall, J. (1980). Stress amongst nurses. White collar and professional stress, 19-59.

Mayer, J. D., Salovey, P., Caruso, D. R., \& Sitarenios, G. (2001). Emotional intelligence as a standard intelligence.

Meyer, J. P., \& Allen, N. J. (1991). A three-component conceptualization of organizational commitment. Human resource management review, 1(1), 61-89. http://dx.doi.org/10.1016/1053-4822(91)90011-Z

Meyer, J. P., \& Allen, N. J. (1997). Commitment in the workplace: Theory, research, and application. Sage.

Meyer, J. P., Allen, N. J., \& Smith, C. A. (1993). Commitment to organizations and occupations: Extension and test of a three-component conceptualization. Journal of applied psychology, 78(4), 538. http://dx.doi.org/10. 1037/0021-9010.78.4.538

Mohammadyfar, M. A., Khan, M. S., \& Tamini, B. K. (2009). The effect of emotional intelligence and job burnout on mental and physical health. Journal of the Indian Academy of Applied Psychology, 35(2), 
219-226.

Nikolaou, I., \& Tsaousis, I. (2002). Emotional intelligence in the workplace: Exploring its effects on occupational stress and organizational commitment. International Journal of Organizational Analysis, 10(4), 327-342. http://dx.doi.org/10.1108/eb028956

Slaski, M., \& Cartwright, S. (2002). Health, performance and emotional intelligence: an exploratory study of retail managers. Stress and Health, 18(2), 63-68. http://dx.doi.org/10.1002/smi.926

Tallman, R., \& Bruning, N. S. (2005). Hospital nurses' intentions to remain: Exploring a northern context. The health care manager, 24(1), 32-43. http://dx.doi.org/10.1097/00126450-200501000-00006

Tyler, P., \& Cushway, D. (1998). Stress and wellbeing in healthcare staff: The role of negative affectivity, and perceptions of job demand and discretion. Stress and Health, 14(2), 99-107.

Wong, C. S., \& Law, K. S. (2002). The effects of leader and follower emotional intelligence on performance and attitude: An exploratory study. The Leadership Quarterly, 13(3), 243-274. http://dx.doi.org/10.1016/S 1048-9843(02)00099-1

Wong, D., Leung, S., So, C., \& Lam, D. (2001). Mental health of Chinese nurses in Hong Kong: The roles of nursing stresses and coping strategies. Online Journal of Issues in Nursing, 5(2), 1-22.

Zigmond, A. S., \& Snaith, R. P. (1983). The hospital anxiety and depression scale. Acta psychiatrica scandinavica, 67(6), 361-370. http://dx.doi.org/10.1111/j.1600-0447.1983.tb09716.x

\section{Copyrights}

Copyright for this article is retained by the author(s), with first publication rights granted to the journal.

This is an open-access article distributed under the terms and conditions of the Creative Commons Attribution license (http://creativecommons.org/licenses/by/3.0/). 